\title{
Effectiveness of Restricted Diet with a Plate in Patients with Type 2 Diabetes: a Randomized Controlled Trial
}

\author{
yongwen zhang ${ }^{1}$, Huanhuan $\mathrm{Han}^{2}$, and Lanfang Lanfang ${ }^{3}$ \\ ${ }^{1}$ Affiliation not available \\ ${ }^{2}$ Nanjing University of Chinese Medicine \\ ${ }^{3}$ East Region Military Command General Hospital
}

November 16, 2020

\begin{abstract}
Aims: To evaluate whether the plate model can effectively improve glycemic control and cardio-vascular risk markers in type 2 diabetes mellitus (T2DM), while reducing the time devoted to edu-cation and avoiding weight gain. Methods: The study included 419 participants who were randomly divided into a plate group and a counting group. The plate model included three components: a low-literacy, color leaflet containing the explanation and composition of the plate model, health education, and medical visits. Patients in the counting group received health education, group medical visits, and a paper booklet containing traditional carbohydrate counting education. Primary outcomes were glycemic control and weight. Results: Participants in the plate model reduced HbA1c by $0.7 \%$ in the first three months, and re-duced to a greater extent at six months (1.44\%), but this was not sustained, and HbA1c increased slightly over the following six months. Fasting plasma glucose (FPG) and 2-h postprandial glucose $(2 \mathrm{hPG})$ values were significantly reduced at the endpoint in the plate model $(9.25 \pm 1.72 \%$ vs. $7.44 \pm 0.88 \%$, $\mathrm{P}=0.008 ; 12.07 \pm 2.94$ vs. $8.35 \pm 1.99 \% ; \mathrm{P}=0.004$ ); however, the $2 \mathrm{hPG}$ values decreased most significantly. Total cholesterol (TC) and low-density lipoprotein cholesterol (LDL-C) levels decreased significantly in the plate group, which occurred at six months and lasted for 12 months. Conclusions: The plate model is more effective than counting education, associated with less weight gain, allows dietary freedom to most of patients, promotes behavior change, and requires less time for education. Plate model has the potential to improve education of those with low health literacy by reducing reading demands.
\end{abstract}

\section{Hosted file}

Effectiveness of restricted diet with a plate model.pdf available at https://authorea.com/ users/376162/articles/493220-effectiveness-of-restricted-diet-with-a-plate-in-patientswith-type-2-diabetes-a-randomized-controlled-trial 


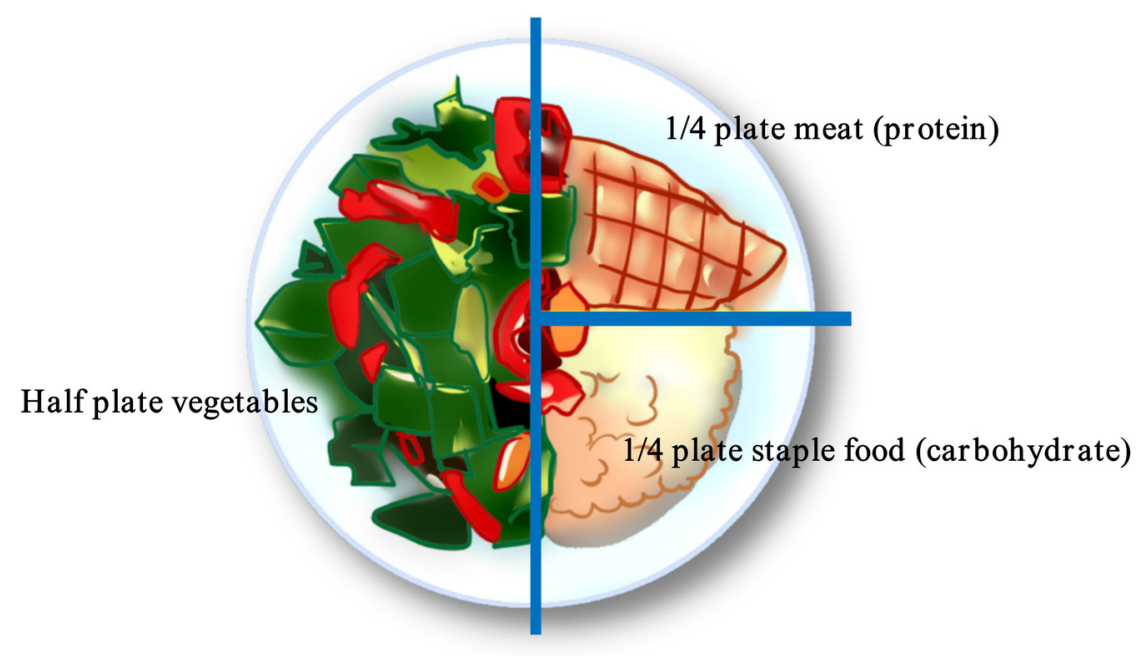

Figure 1 Restricted diet with a plate
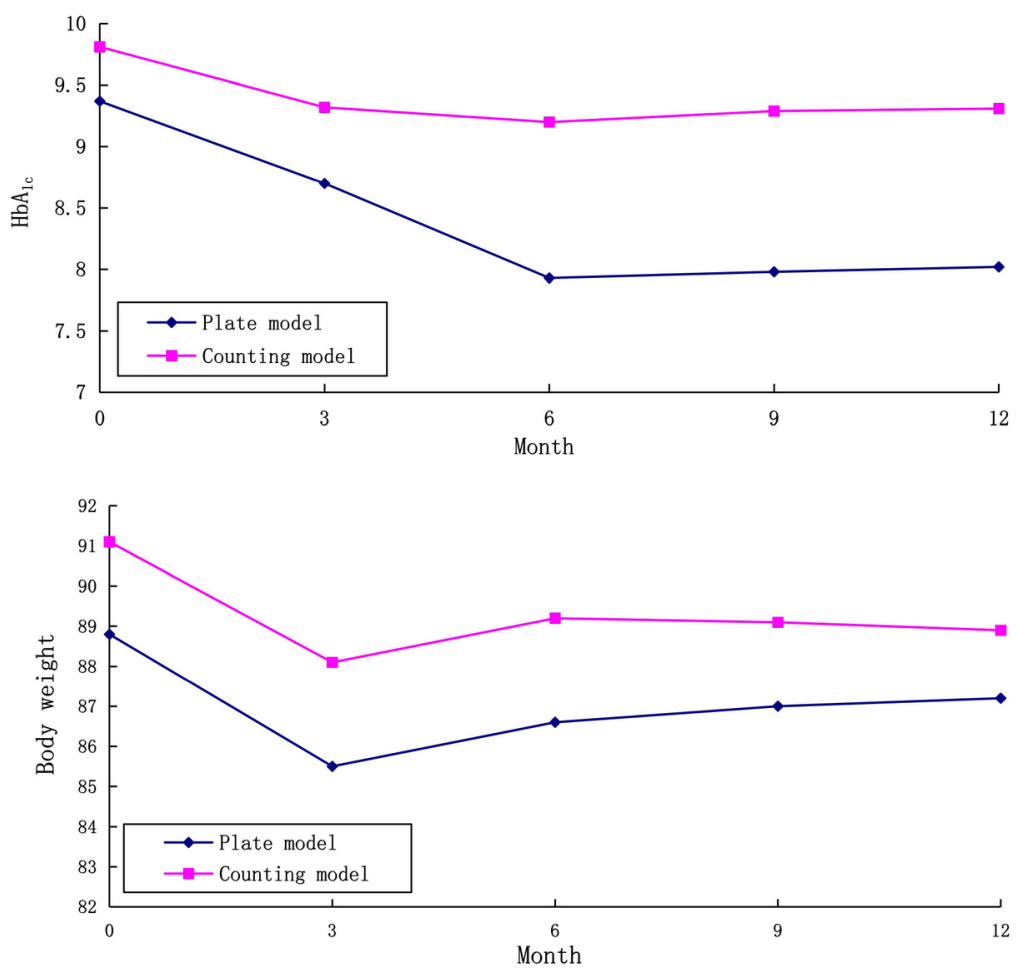

Figure 2 Changes in $\mathrm{HbA}_{\mathrm{lc}}$ and Body weight over the course of the study.

\section{Hosted file}

Table.pdf available at https://authorea.com/users/376162/articles/493220-effectiveness-ofrestricted-diet-with-a-plate-in-patients-with-type-2-diabetes-a-randomized-controlledtrial 